\title{
Metabolic disorders and blood fatty acids status in hospitalized very old patients: part I of the Alpha-linolenage study $\star \star \star \star$
}

\author{
Olivier Henry ${ }^{1, \star \star \star}$, Nicole Combe ${ }^{2}$, Carole Vaysse ${ }^{2}$, Carlos Lopez $^{3}$, Fathi Driss ${ }^{4}$, Isabelle Fonseca ${ }^{1}$, \\ Noëmie Simon ${ }^{5}$, Céline Le Guillou ${ }^{5}$, Sylvie Masselin-Silvin ${ }^{3}$, Jean-Philippe David ${ }^{1}$ and François Mendy ${ }^{6}$ \\ 1 Groupe Hospitalier Henri Mondor, Hôpital Emile Roux, AP-HP, 94450 Limeil-Brevannes, France \\ 2 ITERG, Unité de Nutrition, Métabolisme \& Santé, Université Bordeaux 2, 33076 Bordeaux, France \\ 3 Institut de l'Elevage, 149 rue de Bercy, 75595 PARIS, France \\ 4 Laboratoire d'Hormonologie/Génétique Moléculaire, Hôpital Bichat, Claude Bernard, Paris, France \\ 5 ONIDOL, 11 rue de Monceau, 75378 Paris, France \\ ${ }^{6}$ CETIOM, 11 rue de Monceau, 75378 Paris, France
}

Received 1st April 2015 - Accepted 23 April 2015

\begin{abstract}
Background: previous studies showed that hospitalized elderly women had low Polyunsaturated fatty acids (PUFA) intake and concomitantly showed biochemical indices of essential fatty acid (EFA) insufficiency. Objectives: the Alpha-Linolenage study aimed to improve health parameters of hospitalized very elderly patients, aged 85 years. The objective of the Part I of the Alpha-linolenage study was to assess blood fatty acid status and parameters of metabolic disorders of these patients at the baseline. Design: from 2009 to 2011, 188 patients entering the geriatric department of Emile Roux Hospitals, Île-de-France region, France, were included. Data on the lipid status were obtained through analysis of fatty acid compositions of plasma cholesterol esters and erythrocyte phospholipids. Results: because of our inclusion criteria, there was a high prevalence of CV disease, affecting 74\% of our participants. Patients ingested an average of $1586 \mathrm{kcal}$ per day. Fat accounted for $49.2 \mathrm{~g} / \mathrm{d}$. Both LA and ALA intakes were not reached, i.e. on average $5 \mathrm{~g} / \mathrm{d}$ of LA vs. 8-10 g and $1.2 \mathrm{~g} / \mathrm{d}$ of ALA $v s$. 2-2.5 g recommended, respectively. The LA and ALA blood status reflected this situation; their contents were lower than those waited under sufficient EFA diet. Conclusion: in very elderly patients a status of chronic disease may generate $\mathrm{CV}$ or mortality risk factors. A low fat intake, with both insufficient LA and ALA intakes might favor the harmful role played by de novo lipogenesis, Indeed, a cornerstone of dietary guidelines, i.e. restriction of fat and saturated fat, may be related to risk of disease. The second part of the alpha-linolenage study will aim to improve markers of the metabolic disorders by providing sufficiently lipids.
\end{abstract}

Keywords: Alpha-linolenage study / fatty acids / elderly / ALA / PUFA / rapeseed oil

Résumé - Désordres métaboliques et statut en acides gras du sang chez des patients très âgés hospitalisés : $1^{\text {re }}$ partie de l'étude Alphalinolénage. Contexte : Des précédentes études ont montré que des femmes âgées hospitalisées consommaient peu de d'acides gras poly-insaturés (AGPI) et affichaient de manière concomitante les signes biochimiques d'une insuffisance en acides gras essentiels. Objectifs : L'étude Alpha-linolénage vise à améliorer les paramètres de santé de patients hospitalises, âgés de 85 ans. La première partie de l'étude alpha-linolénage visait à mesurer les concentrations en acides gras du sang et les paramètres de référence (à $T=0$ ) des désordres métaboliques de ces patients. Design : De 2009 à 2011, 188 patients hospitalisés au département gériatrique de l'hôpital Emile Roux (région Île-de-France, France) ont été inclus. Résultats : En raison de nos critères d'inclusion, la prévalence des maladies cardiovasculaire est élevée, affectant $74 \%$ des participants. Les besoins en acides gras linolénique et alpha-linoléique ne sont pas couverts, avec en moyenne $5 \mathrm{~g} / \mathrm{jour}$ de AL (contre $10 \mathrm{~g}$ recommandés) et 1,3-2 g/jour de ALA (contre 2-2,5 g recommandés). Conclusions : Chez nos sujets très âgés, l'existence de maladies chroniques

\footnotetext{
* Supported by grants from ONIDOL (Interbranch organisation for the French oilseed and oil fruit sector) and FranceAgriMer (Platform for dialogue, strategic planning and conciliation for French agricultural and fishing sectors).

$\star \star$ Author disclosures : O. Henry, C. Vaysse, C. Lopez, F. Driss, I. Fonseca, S. Masselin-Silvin, J.P. David have no conflicts of interest; N. Simon and C. Le Guillou are employed by ONIDOL; N. Combe reports ad hoc travel reimbursement and honoraria from Onidol and F. Mendy reports ad hoc consulting fees from CETIOM (Technical Center for Oilseeds) and has received funding in the past from ONIDOL. The funders had no role in the design of the study; management, analysis, or interpretation of the data.
}

$\star \star \star$ Correspondence: olivier.henry@aphp.fr 
est associée à des facteurs de risque cardiovasculaire ou à la mortalité. Des apports insuffisants en acides gras, comme l'acide linoléique ou alpha-linolénique, peuvent être dangereux en induisant une lipogénèse de novo. Le dogme des régimes pauvres en graisses a ainsi peut-être vécu. La seconde partie de cette étude analysera l'évolution des anomalies métaboliques avec la correction des apports lipidiques.

Mots clés : Étude Alpha-linolenage / acides gras / personnes âgées / ALA / AGPI / huile de colza

\section{Introduction}

Frailty presents as a declined ability to respond to stressful events and an increased vulnerability to adverse health outcomes (Fried et al., 2001). The prevalence of frailty is higher in women than in men and increases exponentially with increasing age (Gale et al., 2015). Frailty increases the risk of disability, long-term care and hospitalizations in the elderly and is recognized as an important challenge to improving healthy aging. While frailty is known to be associated with chronic diseases such as cardiovascular disease (CV), metabolic risk factors underlying these associations remain unclear (Ramsay et al., 2014). So, a recent study showed the complex associations between metabolic syndrome and frailty (Lin et al., 2015).

Risk factors such as hypertension, dyslipidemia, obesity, diabetes and insulin resistance have been extensively studied in young adults. Their combination defines the metabolic syndrome, an important CV Risk factor in itself (Wang et al., 2007). However, the significance of these risk factors in the oldest old remains a subject of debate. Whereas obesity is a risk factor for diabetes and $\mathrm{CV}$ disease in young adults, a low body mass index (BMI) has significantly predicted mortality in several elderly populations (Kalmijn et al., 1999; Stevens et al., 1998 de "aortic stiffness"). Furthermore, insulin resistance is considered a common denominator of the metabolic syndrome and type 2 diabetes, and has also been proposed to be an independent risk factor (Pyorala et al., 1998; Reaven, 1988). As insulin resistance may be modified by age, malnutrition, inflammation and chronic disease, the association between malnutrition, inflammation and type 2 diabetes becomes more frequent in older subjects. Paradoxically, in very old patients, positive associations between total mortality and high insulin sensitivity have been observed in prior studies (Protogerou et al., 2007; Vischer et al., 2009). This surprising link between mortality and some of these parameters known as favorable seems to affect a specific category of the population, namely very old subjects ( 85 years and more). Elderly people are at risk of nutritional deficiencies as a consequence of both inadequate food intake and digestive perturbations (Brownie, 2006). In hospitals or nursing-homes, such nutritional risk may affect $60 \%$ of the residents (Stange et al., 2013). Modifications in membrane lipid status have been reported in ageing populations (Schmuck et al., 1998; Babin et al., 1999). These modifications may be due to inadequate lipid nutrient intake, altered fatty acid metabolism, increased lipoperoxidation of polyunsaturated fatty acids (PUFA), reflected by metabolic disorders, such as dysglycemia, dyslipoproteinemia, dyslipidemia and chronic low grade inflammation.

An early study (Schmuck et al., 1998) has shown that hospitalized elderly women had low PUFA intake and concomitantly showed biochemical indices of essential fatty acid (EFA) insufficiency, such as decrease in LA, and increase in monoun- saturated fatty acids (MUFA), in (n-7) fatty acids and in indexes of D6 and D9 desaturase activities. Elsewhere, lower percentages of LA in plasma lipids have been reported in elderly women compared with young women (Babin et al., 1999).

The present study (Part I of the Alpha-linolenage study, at baseline) provides an insight in the clinical characteristics of French elderly patients. Its purpose was to assess relationships between the blood fatty acid status and some parameters of metabolic disorders, according to sex. Part II of the study will investigate the impact of an diet enriched in alpha-linolenic acid (18:3 (n-3), ALA), on parameters of metabolic disorders, in these hospitalized patients, by providing ALA via rapeseed oil as the refined oil and margarine containing rapeseed oil.

\section{Participants and methods}

\subsection{Study cohort}

From 2009 to 2011, 188 patients entering the geriatric department of Emile Roux Hospitals, Ile de France region, France, were included in the Alpha-linolenage study with respect to the following inclusion criteria: age $\geqslant 65$ years old; past history of $\mathrm{CV}$ disease involving either coronary heart disease, cerebrovascular disease, hypertension, or any other $\mathrm{CV}$ events of the upper or lower limbs, thoracic or abdominal aorta, or renal arteries; Mini Mental Status Examination greater 15/30; and willingness to give a written informed consent to participate in this study. The Alpha-linolenage study was approved by the Committee for the Protection of Human Subjects in Biomedical Research of Henri Mondor Hospital (Ile de France). Written informed consent was obtained from all participants after relevant information was provided to them and/or to their relatives. Only the parameters that are relevant to the present analysis are presented here.

\subsection{Measurement of blood pressure and clinical parameters}

The measurements were performed in the morning, after an overnight fast, with each patient in the supine position. Brachial BP was measured after 15 min of rest using the semiautomatic oscillometric device Dynamap (Kontron). Five measurements $2 \mathrm{~min}$ apart were averaged, as described previously (Protogerou et al., 2007). Pulse pressure (PP) and pulse wave velocity (PWV) were used as markers of arterial stiffness. Pulse pressure (PP) was defined as systolic blood pressure (SBP) - diastolic blood pressure (DBP). Aortic pulse wave velocity (PWV) was determined using the foot-to-foot method as described previously (Asmar et al., 1995, Complior, Colson). The superficial distance covered by the pulse wave was measured directly from the carotid to the femoral artery. This method for distance assessment may overestimate PWV by $2 \mathrm{~m} / \mathrm{s}$ on average. 
Height was estimated from the knee height according to Chumlea et al., 1998: height $=78.31+(1.94$ knee height $(\mathrm{cm}))$ $-(0.14 \times$ age $($ years $))$ in men; and height $=82.21+(1.85$ knee height $(\mathrm{cm}))-0.21 \times$ age (years) in women.

Information compiled from a questionnaire filled out at inclusion include gender, age, body mass index (BMI), personal history of CV event, presence of type 2 diabetes, dyslipidemia, hypertension, smoking habits and previous diseases. In all cases, the information agreed with that provided by relatives and/or recorded during their most recent hospitalization.

\subsection{Medications}

The participants' antihypertensive drugs included diuretics (29.6\%), calcium-channel antagonists $(25.4 \%)$, angiotensinconverting enzyme inhibitors, (35.4\%), beta-blockers, $26 \%$ ), alpha-blockers $(0.5 \%)$, and centrally acting agents $(3.1 \%)$ either alone or in combination. In addition $33.3 \%$ were being medically treated for dyslipidemia with statins and $16 \%$ were being medically treated for type 2 diabetes (including sulphonamides, and/or biguanides and/or insulin).

\subsection{Biological analysis}

Venous blood samples were obtained in subjects after an overnight fast. Thereafter, determination of routine biochemistry and lipid profile by standard methods was performed. Fasting glucose was assayed by the glucose-oxidase method. Insulin was measured with the IMx system (Abbott Diagnosis, Rungis, France) (Gallois et al., 1996). One index was used to calculate insulin sensitivity: HOMA-IR (Homeostatic Model Assessment of Insulin resistance) $\left(I_{0} \times G_{0}\right) / 22.5$, where $I_{0}=$ fasting insulin (Micro $\mathrm{U} / \mathrm{ml}$, and $G_{0}=$ fasting glucose (mmol/L), (Matthews et al., 1985).

\subsection{Fatty acids analysis}

Venous blood samples were drawn into tubes containing ethylene-diamine-tetra-acetic acid (EDTA) as the anticoagulant. The plasma $(2 \mathrm{ml})$ was removed within $30 \mathrm{~min}$ and the erythrocyte mass was washed three times in isotonic sodium chloride solution. Thereafter, the plasma and erythrocyte samples were stored at $-80{ }^{\circ} \mathrm{C}$ until further analysis. All samples were thawed only once when the lipids were extracted by solvents.

Total lipids from plasma were extracted with 20 vol of chloroform/methanol (2:1, v:v) and several washes according to the method of Folch et al., 1957. The plasma CE were separated from the other plasma lipids by preparative TLC by using Silica Gel G plates and a hexane:ethyl ether:acetic acid (80:20:1, v:v) development solvent. The band of CE was visualized under ultraviolet light after staining with dichlorofluorescein $(0.2 \%$ in an ethanol solution), and scraped for a chloroform extraction. Fatty acids of this lipid fraction were prepared by using a $\mathrm{NaOH}$ saponification step at $100{ }^{\circ} \mathrm{C}$ for $60 \mathrm{~min}$ followed by a HCL acidification step. Then fatty acids were methylated by using a 14\% BF3 - methanol solution according to the method of Morrison and Smith (1964), to obtain the corresponding fatty acid methyl esters (FAME) for further GC analysis.
Erythrocyte lipids were extracted with isopropanol according to the method of Peuchant et al., 1989. Total phospholipids (TPL) and phosphatidylethanolamine (PE) of erythrocytes were separated by preparative TLC on Silica Gel G plates by using hexane:ethylether $(60: 20, \mathrm{v}: \mathrm{v})$ and chloroform: methanol: $\mathrm{H}_{2} \mathrm{O}$ (75:25:3, v:v) development solvents, respectively. The lipid fractions were visualized under ultraviolet light and scraped for transmethylation according to the method of Morrison and Smith. FAME compositions of both plasma CE and erythrocyte TPL and PE were determined by highresolution capillary GC with a Trace Ultra-Thermo electron Corp - chromatograph equipped with a flame ionization detector kept at $280{ }^{\circ} \mathrm{C}$. FAME were separated on a capillary column (BPX 70; $60 \mathrm{~m} \times 0.25 \mathrm{~mm}$ i.d., $0.25 \mu \mathrm{m}$ film thickness; SGE, Ltd, France) using helium as the carrier gas (inlet pressure: $110 \mathrm{kPa}$ ) as previously described (Couëdelo et al., 2011). Briefly, the split ratio was $1 / 70$. The column temperature was programmed from 150 to $190{ }^{\circ} \mathrm{C}$ at $1.5{ }^{\circ} \mathrm{C} / \mathrm{min}$ and held at $190{ }^{\circ} \mathrm{C}$ for $30 \mathrm{~min}$, and increased to $225^{\circ} \mathrm{C}$ at $10{ }^{\circ} \mathrm{C} / \mathrm{min}$ and held at $225{ }^{\circ} \mathrm{C}$ until completion of the analysis. The injection port was maintained at $250{ }^{\circ} \mathrm{C}$. The gas chromatographic peaks were integrated using a SP 4400 integrator (Spectra Physics, San Jose, CA). The fatty acid results were expressed as weight percentages of fatty acids detected with chain lengths from 14 to 24 carbon atoms. Fatty acids from Sigma France (Saint Quentin Fallavier, France) and natural extracts of known composition were used as standards for column calibration. The variation in peak area between two injections was less than $2 \%$.

\subsection{Definitions}

Dysglycemia, defined using the following criteria: elevated fasting glucose $(>6.4 \mathrm{mmol} / \mathrm{L})$ or previously diagnosed diabetes or using antidiabetic agents or insulin. Low grade inflammatory syndrome based on the orosomucoïde concentration $(>1.2 \mathrm{~g} / \mathrm{L})$. Metabolic syndrome (MetS): adapted from the updated National Cholesterol Education Program Adult Treatment Panel III criteria for Asian Americans (20), as meeting at least three of the following criteria: (1) pulse pressure $\geq 45 \mathrm{~mm}$ $\mathrm{Hg}$ or systolic pressure $\geq 130 \mathrm{~mm} \mathrm{Hg}$ or diastolic pressure $\geq 85 \mathrm{~mm} \mathrm{Hg}$ or using antihypertensive medications; (2) elevated fasting glucose $(>6.1 \mathrm{mmol} / \mathrm{L})$ or previously diagnosed diabetes or using antidiabetic agents or insulin; (3) reduced HDL-C $(<1.03 \mathrm{mmol} / \mathrm{L}$ in men or $<1.30 \mathrm{mmol} / \mathrm{L}$ in women $)$; and (4) elevated TG ( $>1.7 \mathrm{mmol} / \mathrm{L})$.

\subsection{Statistical analyses}

Descriptive statistics are presented as means \pm standard deviations by sex for the characteristics and fatty acid compositions of erythrocytes and plasma of patients. Eighteen fatty acids and the following ratios (18:3(n-6)/18:2(n-6), 20:4(n6)/20:3(n-6), 22:6(n-3)/20:5(n-3), 20:3(n-6)/18:3(n-6), 22:6(n$3) / 22: 5(n-3)$ and $18: 1(n-7) / 16: 1(n-7))$ were analyzed in plasma $\mathrm{CE}$ and in TPL and PE of erythrocytes. For dysglycemia and LDL-C, pairwise comparisons were derived using Tukey test. In case of interactions between sex and syndromes or variables, the analysis of variance was realized by sex. Transformation was used for distributional reasons. Statistical analyses were performed by using SAS software, release 9.3. 
Table 1. Characteristics of study patients.

\begin{tabular}{cccccc}
\hline & \multicolumn{3}{l}{ Men $(n=48)$} & \multicolumn{3}{l}{ Women $(n=140)$} & \\
\cline { 2 - 5 } & means & SD & means & SD & $p$ \\
\hline Age, years & 83.1 & 8.0 & 84.7 & 6.9 & 0.185 \\
BMI, kg/m & 24.5 & 4.6 & 24.4 & 6.0 & 0.916 \\
Systolic BP, mmHg & 127 & 25 & 131 & 21 & 0.28 \\
Diastolic BP, mmHg & 65 & 12 & 62 & 12 & 0.137 \\
HDL-C, mmol/L & 1.11 & 0.28 & 1.25 & 0.36 & $\mathbf{0 . 0 1 5}$ \\
LDL-C, mmol/L & 2.87 & 0.76 & 3.28 & 1.16 & $\mathbf{0 . 0 2 3}$ \\
Triglycerides, mmol/L & 1.22 & 0.48 & 1.57 & 0.72 & $\mathbf{0 . 0 0 2}$ \\
Fasting serum glucose, mmol/L & 7.07 & 2.35 & 6.61 & 2.25 & 0.228 \\
Fasting serum insulin, pmol/L & 22.16 & 28.90 & 20.07 & 28.00 & 0.659 \\
HOMA-IR & 8.03 & 11.62 & 6.77 & 11.30 & 0.509 \\
\hline
\end{tabular}

Data are presented as the mean and SD. BMI - Body Mass Index, HDL-C - HDL cholesterol, LDL-C - LDL cholesterol, HOMA-IR HOmeostatic Model Assessment of Insulin Resistance.

\section{Results}

\subsection{Characteristics of study participants}

The study cohort was composed of 188 subjects (48 men and 140 women) with mean age \pm SD of $83 \pm 8$ y for men and $85 \pm 7 \mathrm{y}$ for women. Data on their personal history showed that $66 \%$ of patients were hypertensive, $21 \%$ were diabetic, $32 \%$ had a history of clinical heart failure and $22 \%$ had a history of coronary heart disease. Table 1 compares the main clinical and biological features between men and women. No significant difference was observed according to sex for the following characteristics: age, body mass index (BMI), SBP, DBP, PP and femoral PWV. PP and femoral PWV mean values were $66 \pm 15 \mathrm{mmHg}$ and $10.4 \pm 1.4 \mathrm{~m} / \mathrm{sec}$, respectively.

The values of fasting serum glucose and fasting serum insulin concentrations, and HOMA-IR did not differ significantly between men and women. Whereas, the concentrations of HDL-C, LDL-C and TG were significantly higher in women $(P<0.05)$.

\subsection{Basal Diet Composition}

The hospitalized elderly patients ingested an average of $1586 \mathrm{Kcal}$ per day. Fat, total carbohydrate and protein accounted for $49.2 \mathrm{~g}, 228.6 \mathrm{~g}$ and $60.6 \mathrm{~g}$ per day respectively. We noted that the intake level of LA was about $5.1 \mathrm{~g} / \mathrm{d}$; that of ALA was about $1.2 \mathrm{~g} / \mathrm{d}$.

\subsection{Dysglycemia, inflammation and metabolic syndrome}

Patients were classified according to the criteria of dysglycemia, low grade inflammation and metabolic syndrome, as described in the methods paragraph. Figure 1 describes the prevalence of these metabolic disorders in both sexes. We observed that more men than women suffered from dysglycemia, i.e. $63.8 \%$ vs. $46 \%(P<0.05)$. An increased orosomucoïde value, used as a marker of low grade inflammation, was observed in half of the patients, regardless of sex. Finally, the prevalence of metabolic syndrome in our patients did not differ significantly between the women $(43.5 \pm 3.7 \%)$ and the men $(34.0 \pm 3.6 \%)$.

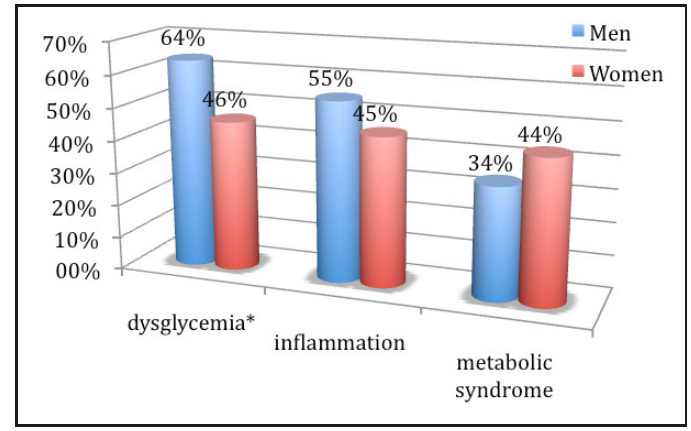

Fig. 1. Prevalence of metabolic disorders in hospitalized patients (140 women and 48 men). Dysglycemia, defined as elevated fasting glucose $(>6.4 \mathrm{mmol} / \mathrm{L})$ or diagnosed diabetes; High orosomucoïde $(>1.2 \mathrm{~g} / \mathrm{L})$ as inflammation; metabolic syndrome. Adapted from the updated National Cholesterol Education Program Adult Treatment Panel III criteria for Asian Americans. * Comparison by sex was performed by the Khi-2 test (values significantly different between women and men; $P<0.05$ ).

\subsection{Fatty acid composition of blood samples}

The erythrocyte fatty acid compositions of both TPL and $\mathrm{PE}$, as well as the plasma CE, are shown for both sexes (Tab. 2). Statistical analyses for comparison according to sex have allowed finding slight differences.

\subsection{Saturated fatty acids}

In the three lipid fractions, the main SFA was palmitic acid (16:0). It accounted for two-thirds of total SFA in erythrocytes, and $90 \%$ in the plasma CE. In this fraction, the 16:0 content was modestly higher in the men than in the women $(P<0.01)$; and the stearic acid (18:0) content of the plasma CE was very low $(<1 \%$ of total FA) whereas it reached $11.5 \%$ in the erythrocyte TPL.

\subsection{Essential fatty acids}

As expected, LA was the most prevalent fatty acid in the plasma CE (45\%). It accounted for 3.7 and $7.2 \%$, respectively in PE and TPL of erythrocytes. ALA was 5 times higher in the plasma CE than in the erythrocyte lipids. This study confirmed the plasma CE is the privileged carrier of ALA in elderly subjects. The EFA levels did not differ according to sex.

\subsection{Long-chain polyunsaturated fatty acids (LC-PUFA)}

Total (n-6) LC-PUFA in both sexes represented on average $55 \%, 31 \%$ and $24 \%$ of total fatty acids of the plasma CE, PE and TPL of erythrocytes, respectively. Conversely to its metabolic precursor (LA), the arachidonic acid (20:4 (n-6); AA) was lower in the plasma CE than in the erythrocyte fractions. No difference was observed according to sex. Highest level of total (n-3) LC-PUFA was observed in the erythrocyte PE $(12.4 \%)$ vs. $7.3 \%$ in the erythrocyte TPL, and $2.5 \%$ in the plasma CE, of both sexes. The most prevalent (n-3) LC-PUFA in the erythrocyte PE was docosahexaenoic acid (22:6(n-3), DHA) i.e. $7.2 \pm 1.4 \%$, followed by docosapentaenoic acid (22:5(n-3), DPA) i.e. $4.0 \pm 0.6 \%$, whereas the most prevalent (n-3) LC-PUFA in the plasma CE was eicosapentaenoic acid 


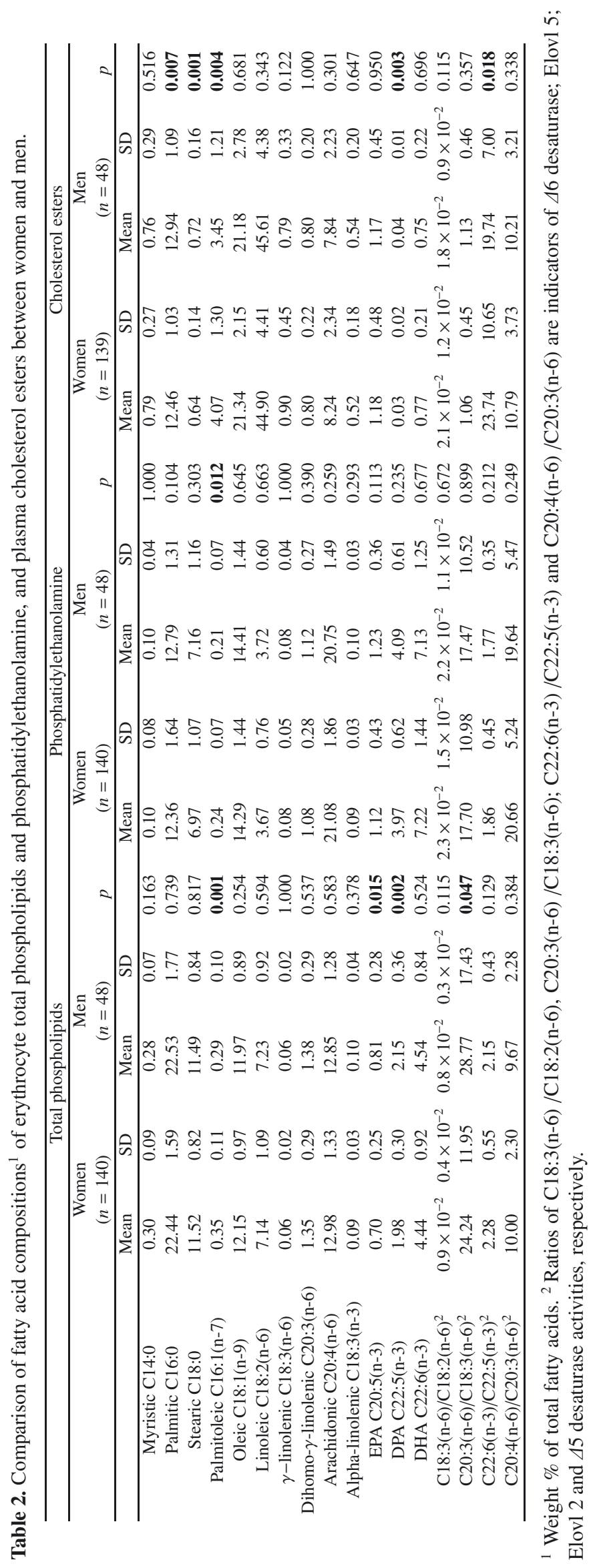


(20:5(n-3), EPA) i.e. $1.2 \pm 0.5 \%$. We observed that EPA and DPA were slightly higher in the men than in the women $(P<$ 0.05 and $P<0.01$, respectively).

\subsection{Fatty acid ratios as enzyme activity markers}

Traditionally, activities of both desaturases and elongases have been estimated by using fatty acid product-to-precursor ratios. In order to assess these enzyme activities in our elderly population, the following ratios are reported in Table 2: 20:3(n6)/18:3(n-6) for assessing Elovl 5 activity, 18:3(n-6)/18:2(n6), 22:6(n-3)/22:5(n-3) and 20:4(n-6)/20:3(n-6) for assessing D6-desaturase, Elovl 2 and D5-desaturase activities, respectively. Results have indicated no difference for both D5 and D6 desaturase activities, according to sex. The Elovl 5 activity estimated in the erythrocyte TPL and the plasma CE was significantly higher in the men. Whereas the Elovl 2 activity, measured in the plasma $\mathrm{CE}$, was significantly higher in the women.

\section{Discussion}

\subsection{Limits of the study}

The first part of the ALPHALINOLENAGE study aimed to assess blood fatty acid status and parameters and metabolic disorders in hospitalized very elderly patients. Our study had some peculiarities that need to be detailed. First, and because of our inclusion criteria, there was a high prevalence of CV disease, affecting $74 \%$ of our participants, which might potentially limit the extrapolation of our results to other elderly populations. However, similar prevalence of $\mathrm{CV}$ diseases were previously reported (Vischer et al., 2009; Blacher et al., 2012). Second, our population was very old: mean age was $84 \pm 7$ years; range: $65-100$ years. This major trait could be responsible for a number of $\mathrm{CV}$ and/or biological peculiarities that were not particularly related to atherosclerosis, dysglycemia, or dyslipidemia, but more related to "unsuccessful" ageing and to chronic diseases related changes (Vischer et al., 2009).

\subsection{Arterial pulse pressure}

Arterial pulse pressure is an independent factor of cardiovascular and notably coronary risk. An increased PP is the principal hemodynamic consequence of increased aortic stiffness with age (Protegerou et al., 2007). In our cohort study, mean pulse pressure was $66 \pm 15 \mathrm{mmHg}$, and was similar than mean value found by Blacher et al., 2012, in the PROTEGER study $(66 \pm 18 \mathrm{mmHg})$. In this study, a cohort of very old frail subjects was investigated prospectively (mean age: $85 \pm 7$ years) to delineate for the first time the pathophysiological role of arterial stiffness on total and CV mortality. In this frail elderly cohort, no association of prognosis with SBP and PP was observed. However, in this very aged population, low DBP, which is related with age and arterial stiffness, was associated with mortality.

\subsection{Pulse wave velocity}

The pulse wave velocity (PWV) is the time taken by the pressure wave to travel between two different sites in the arterial tree. Because pulse waves travel faster in stiffer arteries,
PWV is considered to measure arterial stiffness. Its value in the aorta is approximately $10 \mathrm{~m} / \mathrm{s}$ in an elderly individual (60-65 years) at rest, and continues to increase with advancing age. Aortic PWV is a strong and independent predictor of CV risk, particularly in the elderly (Safar, 2010). Mean PWV was lower in our subjects compared with those of PROTEGER study. Although our data could be interpreted with caution, PWV did not differ between survivors and deceased (Blacher et al., 2012). The relations of PUFA to clinical measures such as vascular stiffness are sparse and inconclusive. Kaess et al. (2015), observed that higher red blood cell omega3 content was moderately associated with PWV in a protective direction. In Korean men aged 30-79 years PWV was highest in individuals with lower proportion of LA in serum phospholipids fatty acids (Kim et al., 2013). This result may suggest a potential benefit of sufficient of LA in diet. On the other hand, Anderson et al. (2009), in 174 non-diabetic participants aged 45-74 years, demonstrated that individuals with higher PUFAS in serum phospholipids, e.g., EPA and DHA, had lower arterial stiffness as measured by PWV. This is consistent with our results. Indeed, of our patients with PWV $>12 \mathrm{~m} / \mathrm{s}$, EPA was higher in PE $(+14 \%)$ in both sex, but was lower in TPL and EC only in women ( $-16 \%$ and $-13 \%$, respectively).

\subsection{Basal diet composition and fatty acid composition of blood samples}

Diet consumed by patients provided 1586 Kcal per day, with a low fat intake (47.6 g per day) compared with recommendation for the French population (70-80 g/d for women and 85-98 g/d for men) (Legrand et al., 2011). Thus, both LA and ALA intakes were not reached, i.e. on average $5 \mathrm{~g} / \mathrm{d}$ of LA vs. $8-10 \mathrm{~g}$ and $1.2 \mathrm{~g} / \mathrm{d}$ of ALA vs. 2-2.5 g recommended, respectively. The decrease in circulating LA in response to a decreased intake of LA is well documented in elderly (AsciuttiMoura et al., 1988; Babin et al., 1999; Schmuck et al., 1998). This EFA has been found high predictor of low fat diet (King et al., 2006). Babin et al. (1999), showed that LA percentage in the plasma CE was positively correlated with intake $(r=0.26)$, as confirmed by data reported by Raatz et al. (2001), and King et al. (2006). In this last study, postmenauposal women aged 63 years consumed a low fat diet providing $7 \mathrm{~g} \mathrm{LA} / \mathrm{d}$ which led to a decrease by $10 \%$ of the LA content of plasma CE, from $50 \%$ to $45 \%$ of total fatty acids, compared with a moderate fat diet providing $10 \mathrm{~g} \mathrm{LA} / \mathrm{d}$. Our results agree with these observations; the LA level in the plasma CE was on average $44.9 \%$ in our old women who consumed $5 \mathrm{~g} \mathrm{LA} / \mathrm{d}$. Similar impact has been found in erythrocytes of the postmenauposal women; their LA content decreased by $11 \%$ after the low fat diet, from $8.5 \%$ to $7.9 \%$. In our patients, the LA content of erythrocyte TPL was $7.2 \%$. As for LA, it has been reported the ALA level in plasma CE reflects the ALA intake $(7,23)$. With a consumption of $1.2 \mathrm{~g} \mathrm{ALA} / \mathrm{d}$, the ALA content of the plasma $\mathrm{CE}$ of our patients reached $0.53 \%$ of total fatty acids, similar to that observed $(0.6 \%)$ in the postmenauposal women who consumed $1.1 \mathrm{~g} / \mathrm{d}$. Concerning LC-PUFA, we noted that AA represented on average $8 \%$ in the plasma CE of our patients. King et al. (2006), have found that a low fat diet increased the AA content of plasma CE, from $8 \%$ to $8.4 \%$. Similar data have been reported (Raatz et al., 2001). The profile of (n-3) 
LC-PUFA found in our elderly women was the same as that observed in the postmenauposal women study which demonstrated no significant impact on the (n-3) LC-PUFA content of erythrocytes and plasma $\mathrm{CE}$, after fat intake modification (King et al., 2006).

\subsection{Dysglycemia}

Dysglycemia observed in our patients was characterized by an elevated fasting serum glucose concentration without large deviation between subjects. So, it seems the serum glucose concentration was partially controlled. Conversely, insulin concentration was very scattered, same as the HOMA-IR value. Therefore, insulin concentration seemed to impact the HOMA-IR value more than glycemia. Insulin might allow controlling partially glycemia. Tabak et al. (2009), observed that a compensatory period, when insulin secretion increases to compensate insulin resistance without any major changes in glucose values, can be long; the patients suffering from the syndrome of the insulin-resistance became type 2-diabetics in approximately 13 years. Interestingly, in our diabetic subjects, those who used antidiabetic agents had higher levels of arachidonic acid and DHA $(+16 \%$ and $+14 \%$, respectively) but only in EC. Nevertheless, type 2 diabetes is significant risk factor for mortality in the elderly (Ayaz et al., 2014; Blacher et al., 2012).

\subsection{Inflammation}

Half of our patients presented an increased level of orosomucoide $(>1.2 \mathrm{~g} / \mathrm{L})$. Inflammation plays an important role in ageing. Consequently, elderly population was characterized by chronic low grade inflammation. In a previous study, we have found that the increase in plasma levels at admission of both CRP and orosomucoid was associated with in-hospital mortality in an identical population of hospitalized patients (Henry et al., 2003). Furthermore, our findings supported the hypothesis that orosomucoid was superior to CRP in mortality risk assessment strategies for elderly patients. The PROTEGER study confirmed the harmful role played by inflammation and orosomucoid level on mortality of hospitalized elderly (Blacher et al., 2012).

\subsection{Dyslipoproteinemia}

Half of our patients presented a decreased HDL-C value, and $33 \%$ had a critical low level of LDL-C $(<2.59 \mathrm{mmol} / \mathrm{L})$. We have compared our results to data provided by ENNS study (De Peretti et al., 2013), which concern a large range of age (from 18 to $74 \mathrm{y}$ ). This study demonstrated that the LDL-C concentration changes during the life and the proportion of the subjects who had a low LDL-C concentration decreases from $47 \%$ in young adults $(<34$ y) to $8 \%$ in adults (45-54 y) then increases until $26 \%$ at the elderly (65-74 y). In our older subjects $(85 \pm 8 \mathrm{y})$, this proportion was even higher compared to younger subjects (65-74 y), confirming the scheme in $U$ curve according to the age for the plasma LDL-C concentration. Moreover, in the PROTEGER study, CRP was associated with low HDL-C and a high HOMA-IR index (Vischer et al., 2009). This observation strongly suggest that cardiometabolic risk factors, including insulin sensitivity, are modified by inflammation.

\subsection{Metabolic syndrome}

Among our patients, $41 \%$ suffered from MetS. There was no gender significant difference even if there was a trend, namely more women than men seemed to be affected, as observed in a cohort study (Vishram et al., 2014) where the prevalence of MetS was $20 \%$ at age 50, regardless of gender, but $37 \%$ vs. $22 \%$ at age 70 in women and in men, respectively. In patients suffering from MetS, 18:0 was higher, but inversely, 16:1 n-7 was lower. However, in a recent study, sixteen men and women 30-66 years old who had metabolic syndrome participated in a controlled dietary intervention: six diets were developed that spanned a range of carbohydrate from 50 to $350 \mathrm{~g} /$ day with concomitant decreases in total and saturated fat (Volk et al., 2014). The proportion of palmitoleic acid (which is known to be a biomarker associated with increased risk of insulin resistance and MetS) in plasma triglyceride and CE was significantly and uniformly reduced as carbohydrate decreased, and then gradually increased with higher carbohydrate diet. Our old patients with MetS had lower levels of palmitoleic acid in PE and in CE $(-14.5 \%$ and $-10.7 \%$, respectively), but not in TPL.

\section{Conclusion}

Our present study indicates that in very elderly patients a status of chronic disease may generate and/or accentuate $\mathrm{CV}$ or mortality risk factors such as dysglycemia, insulin resistance, inflammation or metabolic syndrome. Diet consumed by these patients provided a low fat intake, with both insufficient LA and ALA intakes. This low fat diet conditions might favor the harmful role played by de novo lipogenesis, and there is a need to better understand the relationship between dietary and plasma fatty acids in this population. Indeed, a cornerstone of dietary guidelines, ie restriction of fat and saturated fat, is now being questioned in large part because low fat diet may be related to risk of disease. The second part of the alpha-linolenage study will aim to improve markers of the metabolic disorders by providing sufficiently lipids. Both diets, enriched in linoleic acid and enriched in alpha-linolenic acid/ oleic acid will be tested in these very elderly subjects.

\section{References}

Anderson SG, Sanders TAB, Cruickshank JK. 2009. Plasma fatty acid composition as a predictor of arterial stiffness and mortality. Hypertension 53: 839-845.

Asciutti-Moura LS, Guilland JC, Fuchs F, Richard D, Klepping J. 1988. Fatty acid composition of serum lipids and its relation to diet in an elderly institutionalized population. Am. J. Clin. Nutr. 48: 980-987.

Asmar R, Benetos A, Topouchian J, et al. 1995. Assessment of arterial distensibility by automatic pulse wave velocity measurement: validation and clinical application studies. Hypertension 26: 485-490.

Ayaz T, Sahin SP, Sahin OZ, Bilir O, Rakici H. 2014. Factors affecting mortality in elderly patients hospitalized for nonmalignant reasons. J. Aging Res. 2014: 1-7.

Babin F, Abderrazik M, Favier F, et al. 1999. Differences between polyunsaturated fatty acid status of non-institutionalised elderly women and younger controls: A bioconversion defect can be suspected. Eur. J. Clin. Nutr. 53: 591-596. 
Blacher J, Protegerou AD, Henry O, et al. 2012. Aortic stiffness, inflammation, denutrition and type 2 diabetes in the elderly. Diabetes. Metab. 38: 68-75.

Brownie S. 2006. Why are elderly individuals at risk of nutritional deficiency? Int. J. Nurs. Pract. 12: 110-118.

Chumlea WC, Guo SS, Wholihan K, Cockram D, Kuczmarski RJ, Johnson CL. 1998. Stature prediction equations for elderly nonHispanic white, non-Hispanic black, and Mexican-American persons developed from NHANES III data. J. Am. Assoc. 98: 137-142.

Couëdelo L, Boué-Vaysse C, Fonseca L, et al. 2011. Lymph absorption of $\alpha$-linolenic acid in rats fed flaxseed oil-based emulsion. Br. J. Nutr. 105: 1026-1035.

De Peretti C, Pérel C, Chin F, et al. 2013. Cholestérol LDL moyen et prévalence de 'hypercholestérolémie LDL chez les adultes de 18 à 74 ans, Étude nationale nutrition santé (ENNS) 2006-2007, France. Bull Epidémiol Hebd. ;(31): 378-385.

Expert panel on Detection, evaluation, and treatment of high blood cholesterol in adults. Executive summary of the third report of the national cholesterol education Program (NCEP) (Adult Treatment Panel III). 2001. J. Am. Med. Assoc. 285: 2486-2497.

Folch J, Lees M, Sloane-Stanley GH. 1957. A simple method for the isolation and purification of total lipids from animal tissues. $J$. Biol. Chem. 226: 497-509.

Fried LP, Tangen CM, Walston J, et al. 2001. Cardiovascular health study collaborative research group. J. Gerontol. A. Biol.Sci. Med. Sci. 56: M146-M156.

Gale CR, Cooper C, Sayer AA. 2015. Prevalence of frailty and disability: findings from the English Longitudinal Study of Ageing. Age Ageing 44: 162-165.

Gallois Y, Vol S, Cacès E, Balkau B. 1996. Distribution of fasting serum insulin measured by enzyme immunoassay in an unselected population of 4,032 individuals. Reference values according to age and sex. D.E.S.I.R. Study Group. Données épidémiologiques sur le syndrome d'insulino-résistance. Diabetes Metab. 22: $427-431$.

Henry OF, Blacher J, VerdavaineJ, Duviquet M, Safar ME. 2003. Alpha-1acid glycoprotein is an independent predictor of inhospital death in the elderly. Age Ageing 32: 37-42.

Kaess BM,Harris WS, Lacey S, et al. 2015. The relation of red blood cell fatty cids with vascular stiffness, cardiac stricture and left ventricular function: the Framingham Heart Study. Vasc. Med. 20: $5-13$.

Kalmijn S, Curb JD, Rodriguez BL, Yano K, Abbott RD. 1999. The association of body weight and anthropometry with mortality in elderly men: the Honolulu Heart Program. Int. J. Obes. Relat. Metab. Disord. 23: 395-402.

Kim OY, Lim HH, Lee MJ Kim JY, Lee JH. 2013. Association of fatty acid composition in serum phospholipids with metabolic syndrome and arterial stiffness. Nutr. Metab. Cardiovasc. Dis. 23: 366-374.

King IB, Lemaitre RN, Kestin M. 2006. Effect of a low-fat diet on fatty acid composition in red cells, plasma phospholipids, and cholesterol esters: investigation of a biomarker of total fat intake. Am. J. Clin. Nutr. 83: 227-236.

Legrand P, Morise A, Kalonji E. 2011. Update of French nutritional recommendations for fatty acids. World Rev. Nutr. Diet. 102: $137-143$.
Lin F, Roiland R, Chen DG, Qiu C. 2015. Linking cognition and frailty in middle and old age: metabolic syndrome matters. Int. J. Geriatr. Psychiatry 30: 64-71.

Matthews DR, Hosker JP, Rudenski AS, Naylor BA, Treacher DF, Turner RC. 1985. Homeostasis model assessment: insulin resistance and beta cell function from fasting plasma glucose and insulin concentrations in man. Diabetologia 28: 412-419.

Morisson W, Smith L. 1964. Preparation of fatty acid methyl esters and dimetylacetals from lipids with boron fluoride methanol. $J$. Lipid. Res. 5: 600-608.

Peuchant E, Wolff R, Salles C, Jensen R. 1989. One-step extraction of human erythrocyte lipids allowing rapid determination of fatty acid composition. Anal. Biochem. 181: 341-344.

Protogerou AD, Safar ME, Iaria P, et al. 2007. Diastolic blood pressure and mortality in the elderly with cardiovascular disease. Hypertension 50: 172-180.

Pyorala M, Miettinen H, Laakso M, Pyorala K. 1998. Hyperinsulinemia predicts coronary heart disease risk in healthy middle-aged men: the 22-year follow-up results of the Helsinki Policemen Study. Circulation 98: 398-404.

Raatz SK, Bibus D, Thomas W, Kris-Etherton P. 2001. Total fat intake modifies plasma fatty acid composition in humans. J. Nutr. 131: 231-234.

Ramsay SE, Arianayagam DS, Papacosta O, Lennon LT, Wannamethee DG. 2014. Cardiometabolic and social determinants of frailty: results from a population-based study of elderly British men. Age Ageing 43: ii16.

Reaven GM. 1988. Banting lecture. Role of insulin resistance in human disease. Diabetes. 37: 1595-1607.

Safar ME. 2010. Arterial aging-hemodynamic changes and therapeutic options. Nat. Rev. Cardiol. 7: 442-449.

Schmuck A, Villet A, Payen N, Alary J, Franco A, Roussel AM. 1998. Fatty acid nutriture in hospitalized elderly women. J. Am. Coll. Nutr. 17: 448-453.

Stange I, Poeschl K, Stehle P, Sieber CC, Volkert D. 2013. Screening for malnutrition in nursing home residents: comparison of different risk markers and their association to functional impairment. J. Nutr. Health Aging. 17: 357-363.

Stevens J, Cai J, Pamuk ER, Williamson DF, Thun MJ, Wood JL. 1998. The effect of age on the association between body-mass index and mortality. N. Engl. J. Med. 338: 1-7.

Tabák AG, Jokela M, Akbaraly TN, Brunner EJ, Kivimäki M, Witte DR. 2014. Trajectories of glycaemia, insulin sensitivity, and insulin secretion before diagnosis of type 2 diabetes: an analysis from the Whitehall II study. The Lancet 373: 2215-2221.

Vischer UM, Safar ME, Safar H, et al. 2009. Cardiometabolic determinants of mortality in a geriatric population: is there a "reverse metabolic syndrome"? Diabetes Metab. 35: 108-114.

Vishram JKK, Borglykke A, Andreasen AH, et al. 2014. Impact of age and gender on the prevalence and prognostic importance of the metabolic syndrome and its components in Europeans. The MORGAM Prospective Cohort Project. PLoS One 9: e107294.

Volk BM, Kunces LJ, Freidenreich DJ, et al. 2014. Effects of stepwise increases in dietary carbohydrate on circulating fatty acids and palmitoleic acid in adults with metabolic syndrome. PLoS One 9: e113605.

Wang J, Ruotsalainen S, Moilanen L, Lepisto P, Laakso M, Kuusisito J. 2007. The metabolic syndrome predicts cardiovascular mortality: a 13-year follow-up study in elderly non diabetic Finns. Eur. Heart. J. 28: 857-864.

Cite this article as: Olivier Henry, Nicole Combe, Carole Vaysse, Carlos Lopez, Fathi Driss, Isabelle Fonseca, Noëmie Simon, Céline Le Guillou, Sylvie Masselin-Silvin, Jean-Philippe David, François Mendy. Metabolic disorders and blood fatty acids status in hospitalized very old patients: part I of the Alpha-linolenage study. OCL 2015, 22(3) D305. 